\title{
CHOICE OF APPROPRIATE CONTROL VALUES FOR EFFECTIVE ANALYSES OF DAMAGE DETECTION
}

\author{
MICHAL VENGLÁR ${ }^{1 *}$, MILAN SOKOL ${ }^{1}$
}

\section{Abstract}

The article is devoted to a suitable choice of input parameters for the efficient running of a self-developed code used for damage detection. The code was prepared in Office Excel VBA, which used a non-destructive vibration-based method. The primary aim of the code is to determine the change in bending stiffness by using the FE model updating method, and the aim of the paper is to determine the effect of the input data on the bending stiffness calculations. The code was applied for a numerical model of a steel bar. The steel bar was a simply supported beam with a span of 3.5 $m$. The time of the calculations and precision of the identification were investigated. The values of the time consumption depend on the input values, the desired limit of the accepted error, and the length of the step in every iteration. Data from an experimental model was analysed. The model was made of wooden and plaster boards. The calculations were done in accordance with suitable input data from a parametric study.
Address

1 Department of Structural Mechanics, Slovak University of Technology in Bratislava, Faculty of Civil Engineering, Bratislava, Slovakia

* Corresponding author: michal.venglar@stuba.sk

\section{Key words}

- Parametric study,

- Structural health monitoring

- Damage assessment,

- System identification,

- FE model updating method.

\section{INTRODUCTION}

In recent years, Structural Health Monitoring (SHM), the system identification, or damage detection of bridge structures, as well as other structures, has achieved popularity among researchers (e.g. Wenzel (2009), Chang et al. (2003)). This increased interest is due to many reasons, e.g. increasing security demands, and the aging of bridge structures around the world. According to Ahlborn et al. (2010), Fischer (2016), and Paulik (2014), the average age of bridge constructions in many countries is over 40 years. Higher ages of bridges can result in susceptibility to damage (Orban (2006)) and thereby the risk of an emergency on a bridge, as well as increasing demands for modernization, which is often more expensive. Other reasons for the necessity of modernization are poor maintenance and lack of regular inspections. In some cases (e.g. Agocs and Vanko (2016)), structural health is so critical that it is necessary to destroy the original construction and replace it with a new one. The construction of a new bridge is usually even more costly, but it depends on good decisions made by bridge authorities (Pipanato (2016)). SHM can help avoid the above-described situations and reduce the amount of the overall cost. For this reason, the article is dedicated to the detection of structural damage.

Several approaches using the Finite Element Model Updating (FEMU) method were summarized by Mottershead and Friswell (1993), Carden and Fanning (2004). The FEMU method is applied for damage assessments by neglecting structural damping and using the measured modal parameters in a simple program in MS Office Visual Basic for Applications (Excel VBA). The program has been slightly modified compared to its last published version in Sokol et al. (2015). In this work, the emphasis was placed on an analysis of the input data and its impact on the accuracy of the damage detection. A parametric study was applied to a steel beam with a square cross-section. The edge of the cross-section was $20 \mathrm{~mm}$. The results of the study were applied to the same measured data of the experimental model, which 
consisted of wooden and plaster boards. Finally, the identified moment of inertia was compared to the value identified by the Direct Stiffness Calculation (DSC) method.

\section{PARAMETRIC STUDY}

The theoretical basis and a detailed description of the operation of the program was described by Sokol et al. (2015). However, it has been slightly modified for this case. Each element (i) of the code has its characteristic values of bending stiffness $E I_{(i ;}$; displacement of mode-shape desired $Y_{(i)}$; displacement of mode-shape calculated in the code $Y_{-} Y_{(i)}$ and corresponding slopes $R O T_{(i)}$ for measured and calculated displacements respectively. Slopes $R O T_{(i)}$ have been calculated numerically. $X_{(i)}$ is calculated in every cycle as the value of the difference between the measured and calculated displacements; then the increment $I N C_{(i)}$ or decrement $D E C_{(i)}$ of bending stiffness $E I_{(i)}$ can be determined. Additionally, the code developed in Excel VBA uses multiple input parameters, which affect the accuracy of the results and the length of the time-consuming calculations. The parameter STEP influences a value, which increases $I N C_{(i)}$ or decreases $D E C_{(i)}$ the value of the stiffness of each element $E I_{(i)}$ in a single iteration. The auxiliary error FAULT reflects the sum of the squares of the differences between the desired $Y_{(i)}$ and calculated displacements $Y_{-} Y_{(i)}$ at the nodes $(i)$. All of the calculations ran in a while-loop cycle. The limit value of the auxiliary error (indicated by LIMIT in accordance with Sokol et al. (2015)) is the only condition which determines the calculations in a way that the vector of the calculated displacements corresponds to the desired state of the measured mode-shape, i.e. when the FAULT value is equal to or smaller than LIMIT value.

The results of a modal analysis of the steel beam were used as the input data. The desired mode-shape $Y_{(i)}$ is usually measured, but for this case, the values are from the analysis in the FEM software. Specified changes in the moments of inertia were applied to the 35 elements in the case of the modal analysis and for the damage detection. The length of the element used was $100 \mathrm{~mm}$, so the total beam length was $3500 \mathrm{~mm}$. The second calculations were done in such a way that it changed the height of the cross-section for one element. The smaller height reached only $10 \mathrm{~mm}$ (Fig. 1).

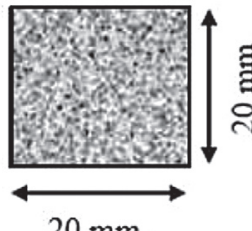

$20 \mathrm{~mm}$

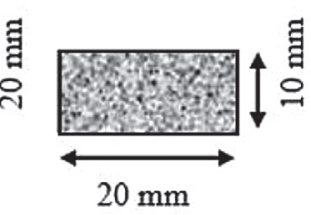

$20 \mathrm{~mm}$
Fig. 1: The cross-section of the elements: intact structure (left) damaged structure (right).

Tab. 1: The accuracy of the calculation - the LIMIT value

\begin{tabular}{|c|c|}
\hline Accuracy & Auxiliary error LIMIT [\%] \\
\hline 1 & 0.5 \\
\hline 2 & 0.05 \\
\hline 3 & 0.005 \\
\hline 4 & 0.0005 \\
\hline 5 & 0.00005 \\
\hline 6 & 0.000005 \\
\hline 7 & 0.0000005 \\
\hline
\end{tabular}

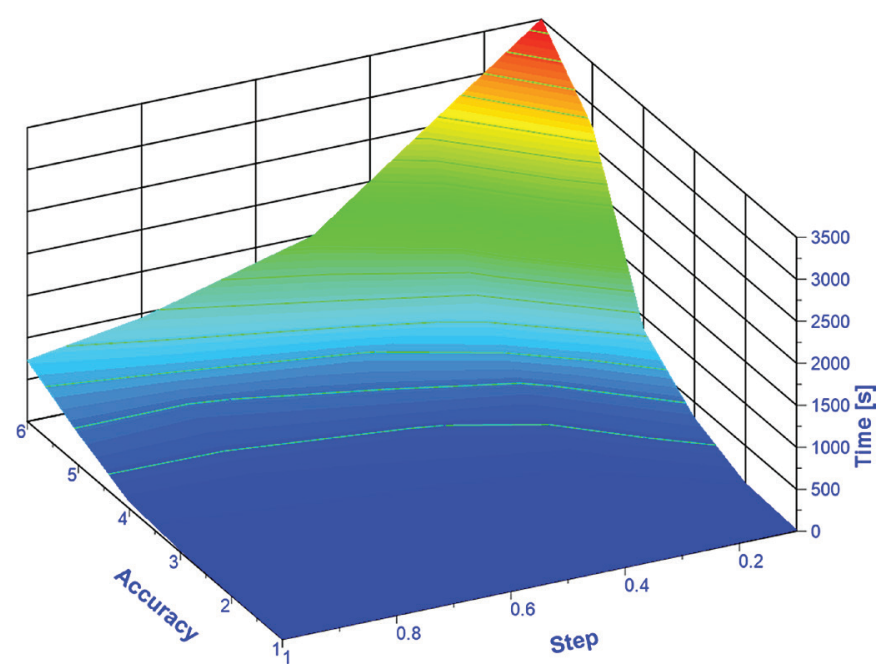

Fig. 2: Computation of the time dependency of the STEP iteration and the required accuracy (the LIMIT value)

The LIMIT value of the auxiliary error was the input parameter (Tab. 1), which was monitored during the parametric study. The second monitored input parameter was the length of the STEP iteration. The range of the considered parameter STEP was assumed to be between 0.1 and 1.0. The values of the parameters (LIMIT, STEP) have an impact on time and accuracy of the computation of the calculations. In the following, these results are shown and commented upon.

The previous figure (Fig. 2) shows the dependency of the computation time on the LIMIT accuracy and the STEP iteration. The graph shows logical results, and it is possible to indicate that in the case of the highest LIMIT accuracy - the smallest auxiliary error (Accuracy 6), the difference does not depend on the value of the STEP iteration. For calculating the difference in the damage detection, the following formula was used:

$$
\text { Error }=\frac{(A-B)}{\max (A, B)}
$$

where A is the identified moment of inertia and B the desired (real) moment of inertia. In this case, the real moment of inertia is approximately $1.67 \mathrm{E}-09 \mathrm{~m}^{4}$.

The results (Fig. 3) show that it is not necessary to choose a very small STEP iteration to achieve the required accuracy in detection. Because of that fact it is possible to reduce the computation time.

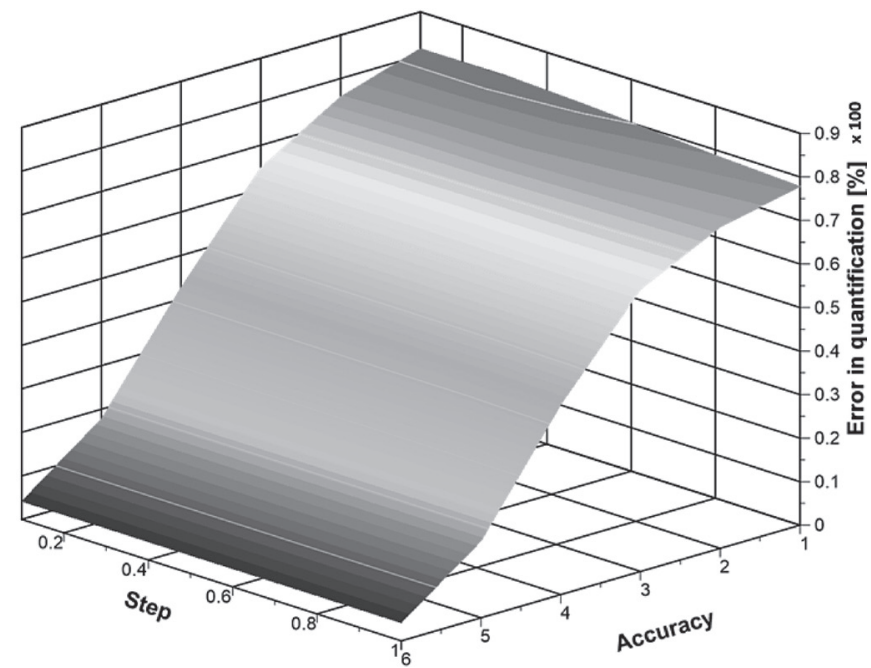

Fig. 3: Dependency of differences in the STEP iteration and the required accuracy (the LIMIT value). 
It was advantageous and suitable to choose as the STEP iteration equal to $1 \mathrm{a}$ parameter for the next computations. The next figure (Fig. 4) shows both of the above-mentioned dependencies for this STEP value. The computation time was plotted on a logarithmic scale due to the better clarity achieved. Analyses with an accuracy value from 1 to 4 (Tab. 1) are below the desired degree of accuracy, and their application is not recommended. Further calculations exceeded the computation time of 6 minutes.

Tab. 2: The achieved accuracy of the calculations.

\begin{tabular}{|c|c|c|c|c|}
\hline Accuracy & $\begin{array}{c}\text { Achieved } \\
\text { accuracy [\%] }]\end{array}$ & $\begin{array}{c}\text { Computation } \\
\text { time }[\mathrm{s}]\end{array}$ & $\begin{array}{c}\text { Identified mo- } \\
\text { ment of inertia } \\
{\left[\mathrm{m}^{4}\right]}\end{array}$ & $\begin{array}{c}\text { Error in } \\
\text { quantification } \\
{[\%]}\end{array}$ \\
\hline 1 & 0.19 & 3.2 & $7.51 \mathrm{E}-09$ & 78 \\
\hline 2 & 0.048 & 6.1 & $6.37 \mathrm{E}-09$ & 74 \\
\hline 3 & 0.0047 & 18.2 & $4.73 \mathrm{E}-09$ & 65 \\
\hline 4 & 0.00046 & 80.5 & $2.96 \mathrm{E}-09$ & 44 \\
\hline 5 & 0.000050 & 374 & $2.03 \mathrm{E}-09$ & 18 \\
\hline 6 & 0.0000050 & 725 & $1.74 \mathrm{E}-09$ & 4 \\
\hline 7 & 0.00000050 & 5118 & $1.67 \mathrm{E}-09$ & 0 \\
\hline
\end{tabular}

On the other hand, the difference dropped below 20\% (Tab. 2). The values under $20 \%$ are acceptable. Finally, the difference for the identified moment of inertia was approaching zero when the too strict LIMIT value of the accuracy (Accuracy 7) was required. The difference is negligible in this case. However, the computation time increased 7 times. Based on the above-mentioned, it can be concluded that the optimum ratio of the computing time and the minimal difference was reached for the level of Accuracy 6. These parameters will also be used in the next section of the paper.

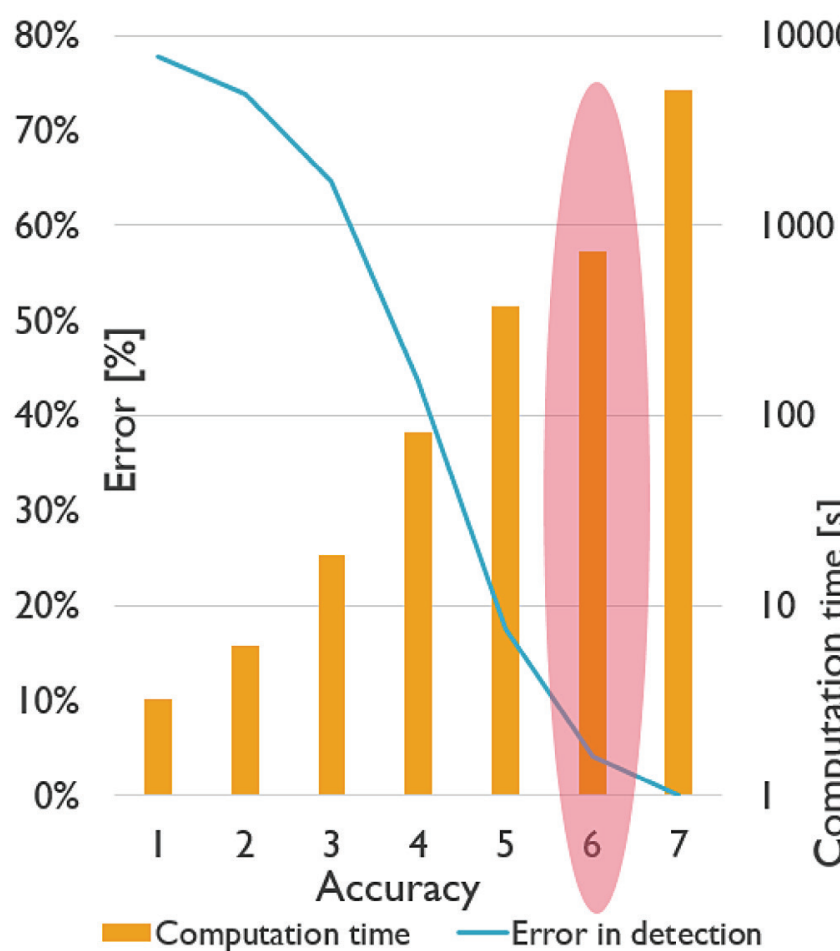

Fig. 4: Dependencies for the STEP equalled to 1.

\section{DAMAGE ASSESSMENT OF THE EXPERIMENTAL MODEL}

The experimental model, as well as the measured accelerations, were assumed in accordance with Venglar and Sokol (2015). The model was made of wooden and plaster boards. The wooden boards were used for the main beam (similar to a U-beam) and the deck was made of plasterboard layers. The specimen was 4 meters long. The accelerations were measured at tenths of the beam lengths (Fig. 5). First, a simple supported beam was measured. The data for the undamaged and the damaged models were acquired.

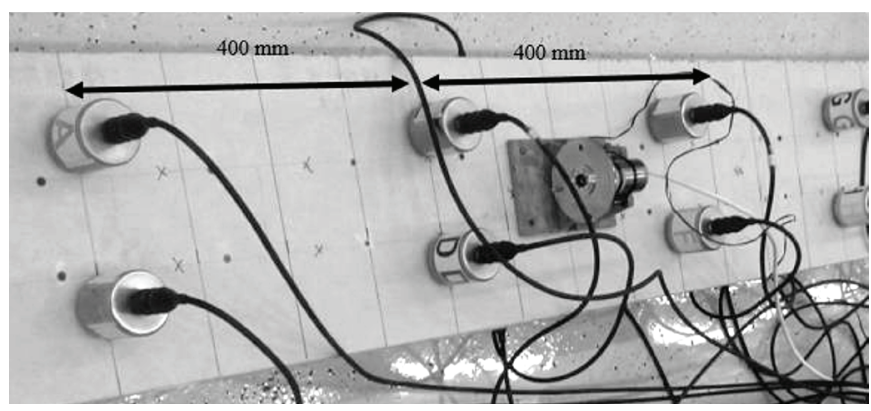

Fig. 5: The placement of accelerometers.

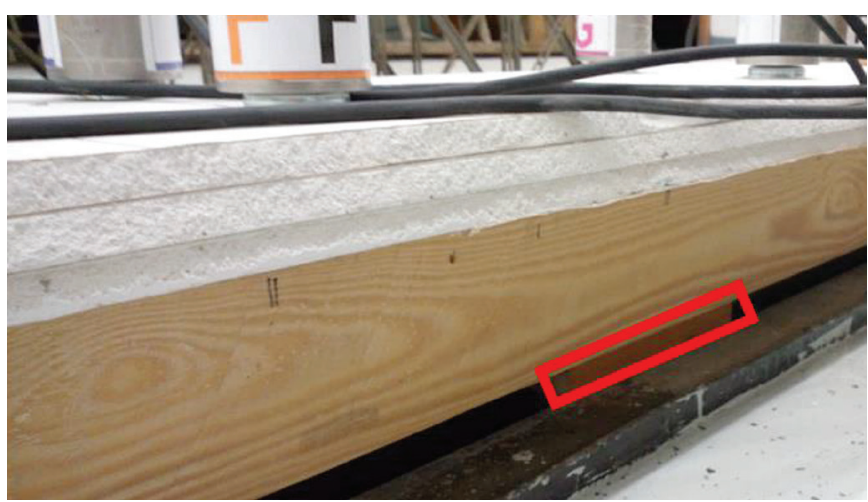

Fig. 6: The stiffener.

The "damage" was simulated with an added stiffener (Fig. 6). The stiffener (a length of $200 \mathrm{~mm}$ ) was added or taken away. The real moment of inertia with the stiffener was $3.75 \mathrm{E}-05 \mathrm{~m}^{4}$. For the system identification, only the first mode-shape was applied, and it was smoothed in accordance with an original procedure from Sokol and Flesch (2005). In comparison with Venglar and Sokol (2015), the satisfactory degree of accuracy of the identification was achieved in this way. The difference in the identified moment of inertia was reduced (Tab. 3). The optimized input values of the parameters for the calculations with Accuracy 6 led to more accurate results (Fig. 7), but the identification was still not good enough with the small difference.

Tab. 3: The comparison of used methods.

\begin{tabular}{|c|c|c|}
\hline Method & $\begin{array}{c}\text { Identified moment } \\
\text { of inertia }\left[\mathrm{m}^{4}\right]\end{array}$ & $\begin{array}{c}\text { Error in } \\
\text { quantification [\%] }\end{array}$ \\
\hline $\begin{array}{c}\text { FEMU in Venglar and } \\
\text { Sokol (2015) }\end{array}$ & $2.47 \mathrm{E}-05$ & -34 \\
\hline FEMU (Accuracy 6) & $3.14 \mathrm{E}-05$ & -19 \\
\hline $\begin{array}{c}\text { DSC in Venglar and } \\
\text { Sokol (2015) }\end{array}$ & $3.53 \mathrm{E}-05$ & -6 \\
\hline
\end{tabular}




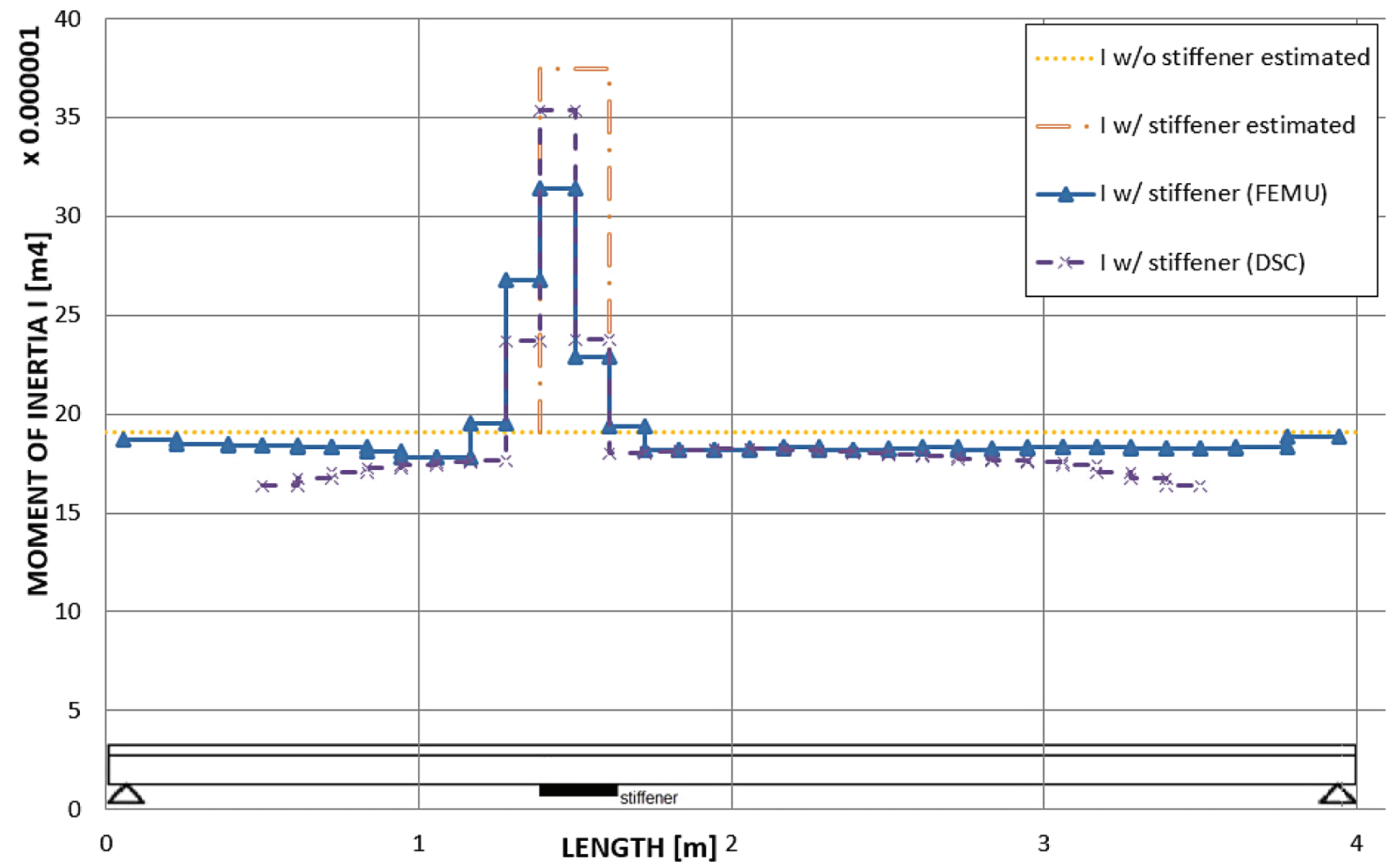

Fig. 7: Comparison of the identification method applied: FEMU method (calculation Accuracy 6) and DSC method.

\section{CONCLUSIONS}

The parametric study verified the computation times, as well as the desired accuracy of the damage assessment. The difference was minimized. The identification of the moment of inertia was successful with acceptable differences in the above-mentioned parameters by using a sufficiently small value of the LIMIT accuracy. The price for the high degree of accuracy was the enormously high time of the calculations. It seems to be reasonable to use the STEP iteration between 0.8 and 1 and the value of the LIMIT of the auxiliary error $0.000005 \%$ (Calculation - Accuracy 6).

The values of both parameters which were found were applied in the subsequent identification of the damage (the addition of a stiffener), which was carried out on the experimental model. The results achieved were better than in Venglar and Sokol (2015). The location of the damage was properly identified, as well as the value of the identified moment of inertia, which was closer to the exact value and closer to the value which was calculated using the Direct Stiffness Calculation method. The difference was already reduced to $19 \%$.

The objective of further work is to optimize the ratio of the computational time and the accuracy of the identification on a general basis, regardless of the structure considered.

\section{Acknowledgements}

This paper has been supported by the Slovak Research and Development Agency (SRDA), i.e., a grant from research program No. APVV-0236-12; it was also created with the support of the Ministry of Education, Science, Research and Sport of the Slovak Republic within the Research and Development Operational Program for the project "University Science Park of STU Bratislava", ITMS 26240220084. 


\section{REFERENCES}

Agocs, Z. - Vanko, M. (2016) Preparation of the Reconstruction of the Old Bridge over the Danube in Bratislava. Procedia Engineering, Vol. 156, pp. 8-15.

Ahlborn, T. M. et al. (2010) The state-of-the-practice of modern structural health monitoring for bridges: A comprehensive review. Michigan TECH Transportation Institute, Michigan, 66 pp.

Carden, E. P. - Fanning, P. (2004) Vibration Based Condition Monitoring: A Review. Structural Health Monitoring, Vol. 3, No. 4, pp. 355-377.

Chang, P. C. - Flatau, A. - Liu, S.C. (2003) Review Paper: Health Monitoring of Civil Infrastructure. Structural Health Monitoring, Vol. 2, No. 3, pp. 257-267.

Fischer, O. (2016) Prestressed Concrete Bridges in Germany - Overview of Current New Structures, Re-analysis and Research Activities to Preserve the Existing Infrastructure Network. Procedia Engineering, Vol. 156, pp. 103-108.

Mottershead, J. E. - Friswell M. I. (1993) Model Updating In Structural Dynamics: A Survey, Journal of Sound and Vibration, Vol. 167, No. 2, pp. 347-375.
Paulik, P. (2014) Bridges in Slovakia. Jaga, Bratislava, 258 pp.

Pipinato, A. (2016) Bridge assessment, retrofit, and management. In: Pipinato, A. (2016) In Innovative Bridge Design Handbook. Butterworth-Heinemann, Boston, pp. 721-757.

Orban, Z. (2006) Increasing the reliability of the assessment of masonry arch bridges by non-destructive testing. Pollack Periodica, Vol. 1, No. 3, pp 45-56.

Sokol, M. - Flesch, R. (2005) Assessment of Soil Stiffness Properties by Dynamic Tests on Bridges. Journal of Bridge Engineering, Vol. 10, No. 1, pp. 77-86.

Sokol, M. et al. (2015) Experience with Structural Damage Identification of an Experimental Bridge Model. Applied Mechanics and Materials, Vol. 769, pp. 192-199.

Venglár, M. - Sokol, M. (2015) Damage Assessment of a Simple Structure. Juniorstav 2015: 17. International Conference of Postgraduate Students. Brno, Czech Republic, 29. 1. 2015. No. 1. Brno: Brno University of Technology [in Slovak].

Wenzel, H. (2009) Health Monitoring of Bridges. John Wiley \& Sons Ltd., Chichester, 652 pp. 